\title{
BMJ Open Laboratory test ordering and results management systems: a qualitative study of safety risks identified by administrators in general practice
}

\author{
Paul Bowie, Lyn Halley, John McKay
}

To cite: Bowie P, Halley L, McKay J. Laboratory test ordering and results management systems: a qualitative study of safety risks identified by administrators in general practice. BMJ Open 2014;4: e004245. doi:10.1136/ bmjopen-2013-004245

- Prepublication history for this paper is available online. To view these files please visit the journal online (http://dx.doi.org/10.1136/ bmjopen-2013-004245).

Received 14 October 2013 Revised 6 January 2014 Accepted 14 January 2014

CrossMark

Department of Postgraduate GP Education, NHS Education for Scotland, Glasgow, UK

Correspondence to Dr P Bowie;

paul.bowie@nes.scot.nhs.uk

\section{ABSTRACT}

Objective: To explore experiences and perceptions of frontline administrators involved in the systems-based management of laboratory test ordering and results handling in general medical practice.

Design: Qualitative using focus group interviews.

Setting: West of Scotland general medical practices in three National Health Service (NHS) territorial board areas.

Participants: Convenience samples of administrators (receptionists, healthcare assistants and phlebotomists).

Methods: Transcript data were subjected to content analysis.

Results: A total of 40 administrative staff were recruited. Four key themes emerged: (1) system variations and weaknesses (eg, lack of a tracking process is a known risk that needs to be addressed).

(2) Doctor to administrator communication (eg, unclear information can lead to emotional impacts and additional workload). (3) Informing patients of test results (eg, levels of anxiety and uncertainty are experienced by administrators influenced by experience and test result outcome) and (4) patient follow-up and confidentiality (eg, maintaining confidentiality in a busy reception area can be challenging). The key findings were explained in terms of sociotechnical systems theory.

Conclusions: The study further confirms the safetyrelated problems associated with results handling systems and adds to our knowledge of the communication and psychosocial issues that can affect the health and well-being of staff and patients alike. However, opportunities exist for practices to identify barriers to safe care, and plan and implement system improvements to accommodate or mitigate the potential for human error in this complex area.

\section{INTRODUCTION}

Workplace systems for managing laboratory test ordering and results handling in primary care are known to be variable, often ineffective and unsafe. ${ }^{1-4}$ However, related research

\section{Strengths and limitations of this study}

- The study involved a number of frontline administrators from a large range of general practices in different geographical areas.

- Qualitative methods were used with a key workforce group to elicit a more in-depth understanding of this complex area of practice.

- The convenience sample is a limitation and National Health Service (NHS) Board areas selected do not reflect the diversity of existing results handling clinical information systems used across Scottish general practice.

to quantify risks and explore patient safety issues appears to be non-existent in the UK and wider Europe, although a very limited number of North American and Australasian studies are published. ${ }^{3-10}$ Arguably this research deficit is a symptom of low levels of interest from policy makers on understanding and resolving patient safety concerns in primary care compared with acute hospitals, although recent UK and European initiatives are encouraging. ${ }^{11} 12$

For patients and their relatives, poor test result handling systems may lead to avoidable harm and distress, delayed treatments, unsatisfactory care experiences and the inconvenience of additional appointments to repeat blood tests or make complaints. ${ }^{1}{ }^{2}$ For general practitioners, missed results and poor test follow-up can lead to delayed clinical judgements on diagnostic and treatment decisions, thereby limiting therapeutic options and potentially impacting on patient safety. ${ }^{3} 4$ The implications may include formal complaints by patients, loss of trust in the doctor-patient relationship, litigation claims for financial compensation and licensure sanctions by medical regulators. ${ }^{9} \quad 13$ At the system level, it is evident that many practices do not have adequate processes for 
systematically tracking test requests, recording test results (both clinically abnormal and normal), and confirming if follow-up action has taken place before results reports are filed or patients are notified. ${ }^{5-7}$

In the UK, and elsewhere, primary care based administrators (most commonly frontline receptionists) work in a demanding and complex role that involves communicating with patients and performing a variety of office duties, many of which have safety importance. ${ }^{14} 15$ Tasks undertaken include preparing repeat prescriptions, handling laboratory test results, deciding on the urgency of home and surgery appointments, controlling patient flow to doctors, making hospital appointments and typing referral letters. ${ }^{14}{ }^{15}$ Often there is a feeling that the duties performed are not appreciated or fully understood by doctors or patients. ${ }^{16}$

The involvement of primary care administrators in health services research, particularly with a focus on safety and improvement appears very limited, with a significant proportion of studies undertaken over a decade ago. Examples include capturing perceptions, feelings and experiences related to: work roles and in-service training ${ }^{14-16}$; influencing access and continuity of $\operatorname{care}^{17}$; risks and effects of violence, and impacts on psychological well-being and work performance and satisfaction $^{18-20}$; improving communication and providing support to enhance clinical care quality ${ }^{21}$ and perceptions of how medication errors can occur. ${ }^{22}$

Given the evidence of system failings and patient harm, and the pivotal work role played by this key group, administrators may have important insights into what can go wrong in this area which clearly merits in-depth study. The aim of this study, therefore, was to explore the experiences and perceptions of frontline primary care administrators directly involved in the systems-based management of laboratory test ordering and results handling, with a particular focus on identifying risks that may impact on patient safety and other relevant quality of care issues.

\section{METHODS}

This qualitative research was undertaken as part of a wider European study to identify, synthesise and integrate a range of evidence based sources of safety-critical issues affecting laboratory test ordering and systems-based results management in primary care. The overall purpose was to develop 'good practice' guidance in this area and build consensus in the UK context and then on a wider European level. ${ }^{23}$

\section{Participants and sampling}

We contacted via email all general practice managers in three west of Scotland National Health Service (NHS) Boards in September 2012 to ask them to invite (on our behalf) representatives from their administrative staff (eg, receptionists, healthcare assistants and phlebotomists) to voluntarily attend focus groups on prearranged dates. NHS boards were selected on the basis that they had a geographical mix (urban, rural and mixed) of practices and were, therefore, more likely to have different systems for managing results (eg, mostly computer based, paper based or mixed computerised and paper systems), which we judged important in reflecting and influencing the types of patient safety risks faced by diverse practices. A convenience sampling strategy was decided on because of the limitations of purposively selecting participants caused by the time-limited nature of the study and the prearranged interview dates.

\section{Focus group interviews}

Five group interviews were held in west of Scotland healthcare settings in Glasgow $(n=3)$, Motherwell $(n=1)$ and Kilmarnock $(\mathrm{n}=1)$. LH moderated each session and assisted the discussion with the aid of a brief topic guide (box 1), informed by issues previously raised in the literature. $^{3} 58$ Participants were asked to view 'patient safety' pragmatically in terms of results handling incidents, or potential incidents, which they would not like to happen to themselves or relatives. They were encouraged to speak freely about their experiences and perceptions of all aspects of the results management systems in their practices. Assurances were given that their views would be treated in the strictest confidence and that they would remain anonymous on transcripts. Sessions lasted between 45 and $70 \mathrm{~min}$ and were digitally recorded and transcribed with permission. Contemporaneous field notes were also taken.

\section{Data analysis}

The transcripts were subjected to conventional qualitative content analysis ${ }^{24}$ - to provide knowledge and understanding of the phenomenon under study ${ }^{25}$-on an iterative basis as data collection progressed. Data were systematically coded, categorised and initial themes identified by LH. Cross-checking of data categories and themes with the transcripts was undertaken by PB to enhance validity. Categories and themes were modified and reduced by merging and linking them after joint discussion between both researchers, with disagreements resolved by consensus. To validate further, we emailed a summary of the draft findings to study participants for critical comment and input, but none provided feedback.

\section{RESULTS}

All 40 staff who agreed to participate from the three discrete Health Board regions approached, attended the five focus group interviews (table 1). We achieved data saturation by the fourth focus group, with the final group interview affirming this. Almost all participants were female $(n=39,97.5 \%)$, with 25 based in urban practices, nine from semirural practices and six from rural practices. 


\section{Box 1 Focus group topic guide ${ }^{358}$}

\section{Study aim:}

To explore experiences and perceptions of frontline administrative staff directly involved in the systems-based management of laboratory test ordering and results handling in general medical practice.

Topic guide questions

Focus group participants were asked:

- About the main problems and frustrations with their practice systems.

- How these might impact on patient care and safety?

- How they feel about their job role and their interactions with other staff groups?

- How they feel about their job role and their interactions with patients?

Areas for Practice Improvement?

Practices may wish to reflect on whether acting on the following issues may improve the safety of their results handling systems:

Training and support for administrative staff on the safe communication of test results to patients and in dealing with reactions and expectations.

Training and support for all staff groups on the basic principles of whole systems thinking and human factors practices.

A standardised process for tracking and reconciling tests ordered with results received that is codesigned, fully understood and used by all relevant staff.

A standardised process for following up patients with clinically significant abnormal results in order to prevent a reliance on the patient to make contact with the practice.

A standardised set of words, terms and phrases-agreed between clinicians and administrators-to enable administrators to communicate and explain common test results to patients using language that is clear, unambiguous and promotes patient safety.

A standardised process that guides how and how often practices attempt to contact patients who require follow-up that is fair and reasonable from a medicolegal perspective.

A standardised process that feasibly minimises the risk of breaching confidentiality by staff when communicating test results to patients face-to-face or over the telephone (including potential redesign of working areas to enhance privacy).

A commitment by doctors and nurses to 'shadow' administrative staff for a short period of time to acquire a better understanding of their job roles and tasks undertaken, and related difficulties and anxieties.

Four principal themes were identified:

1. System variations and weaknesses;

2. Doctor to administrator communication;

3. Informing patients of test results;

4. Patient follow-up and confidentiality.

\section{System variation and weaknesses}

A 'grey area' of mixed computerised and manual processes that underpinned results handling systems was described. For some, particular importance was placed on manually recording all blood tests ordered and reconciling the results when received from the laboratory. For others, the high volume of tests ordered made the workload involved in reconciling tests ordered with results received 'impossible' and this impacted on what was communicated to patients, while there was also a reliance on patients to contact the practice for test results.

Many participants reported using both electronic and paper copy results systems for the same patients to act as a safeguard because of a range of perceived technical and user problems receiving and managing results electronically. The paper copies were also reviewed and then scanned into patients' records and archived. This was viewed as task duplication and a source of frustration because of the reconciliation workload involved. There was consensus that the lack of a tracking system for results handling is a known risk and ongoing concern and needs to be addressed and improved within many GP practices. It was the experience of some participants, that if a patient fails to contact the practice, even if the result is abnormal, they might never receive this information or it will only come to light if they attend in future with a related or different problem.

there could be maybe three or four bloods done and you get two results and you will be relaying the information [that] your results were normal and one or two have still to follow... (Focus Group 2)

it is coded when they have had a sample taken and every day we run a search five days before to see what bloods were taken and make sure they have all come back. (Focus Group 3)

we check that every day we have a blood book... they go through the whole lot and check when it [the result] comes back in. (Focus Group 1)

putting the EMISS [information system] results into the patient's notes and then the Docman results is going into the patient's notes...defeating the purpose. (Focus Group 1)

the onus [is] always on the patient because they are asked to phone back in to get their results... (Focus Group 3)

someone is phoning and we are telling them (the result) is normal and the next day two more come in and there is something wrong with them or one went missing, if that patient didn't phone in for the result and that result has gone missing, if the blood has gone missing before it has even got to the lab, or there has been some sort of lack of communication with the bloods they wouldn't know if it is back or not if the patient phones up and asks for the result and then we would chase the lab and unfortunately the patient doesn't know what bloods are being taken. (Focus Group 4)

\section{Communication between doctor and administrator}

Mixed feelings of anxiety, frustration, pressure or awkwardness emerged often caused by limited, unclear and 


\begin{tabular}{|c|c|c|c|c|c|}
\hline $\begin{array}{l}\text { Focus } \\
\text { group }\end{array}$ & $\begin{array}{l}\text { Location and } \\
\text { NHS Board area }\end{array}$ & $\begin{array}{l}\text { Receptionists } \\
\text { (n) }\end{array}$ & $\begin{array}{l}\text { Healthcare } \\
\text { assistants (n) }\end{array}$ & $\begin{array}{l}\text { Phlebotomists } \\
\text { (main role; } n \text { ) }\end{array}$ & $\begin{array}{l}\text { Total } \\
\text { participants }(n)\end{array}$ \\
\hline 1 & $\begin{array}{l}\text { Glasgow, NHS Greater Glasgow } \\
\text { and Clyde }\end{array}$ & 5 & 1 & 0 & 6 \\
\hline 2 & $\begin{array}{l}\text { Glasgow, NHS Greater Glasgow } \\
\text { and Clyde }\end{array}$ & 7 & 1 & 2 & 10 \\
\hline 3 & $\begin{array}{l}\text { Glasgow, NHS Greater Glasgow } \\
\text { and Clyde }\end{array}$ & 5 & 2 & 2 & 9 \\
\hline 4 & Motherwell, NHS Lanarkshire & 6 & 0 & 0 & 6 \\
\hline 5 & Kilmarnock, NHS Ayrshire & 7 & 2 & 0 & 9 \\
\hline
\end{tabular}

ambiguous test result communications by doctors which would then require further clarification. For many, comments written by doctors on results reports for staff to relay to patients sometimes 'don't make any sense'. Some participants also felt inhibited in what they can say to patients, particularly when advised by doctors never to communicate anything other than what is in their messages. Contacting doctors to clarify the meaning of the message and also ask the patient to telephone back added to workload and inefficiency. Approaching some doctors for clarity could be daunting for some participants in these situations because they may exhibit discourteous behaviours.

A whole series of common terms and words routinely used by doctors in communicating results were described and debated-'satisfactory', 'acceptable', 'normal', 'slightly abnormal', 'no action required'which both staff and patients struggled to make sense of depending on the clinical context, and particularly where the patient queries the result or reacts negatively. For some, this was compounded by a sense of uncertainty in their practices that they are not always doing the same action when communicating results. This limited understanding combined with incomplete information made available to staff impacts on communication difficulties with patients.

he might bite my head off...it depends which GP it is as well...some are more approachable. (Focus Group 5)

a result will say abnormal but it might not necessarily be abnormal to the doctor or where it's maybe satisfactory compared to last month's bloods but it doesn't mean they are normal... (Focus Group 2)

I feel as if they don't really give us enough information to pass it onto the patient...sometimes the doctors are not very detailed (Focus Group 1)

\section{Informing patients of test results}

Differences were apparent in how participants were instructed to inform patients of blood test results and who undertook this task. Some were only 'permitted' to communicate to patients exactly what the doctor had written in the results report, while others were given less guidance on this issue. This was exemplified in one group discussion around cholesterol results which highlighted how some were permitted to pass on actual cholesterol levels while others were instructed never to do this.

Participants had mixed feelings about notifying patients of blood test results. Many described some level of anxiety and uncertainty when communicating test results, with a few describing the process as 'scary' or 'intimidating'. This was especially so when they were new in post, as they were nervous and unsure if they were relaying the correct information, with some suggesting they tried to avoid this task. Some anxiety was related to using unfamiliar medical terminology that has no meaning for them. For some the process is straightforward and unchallenging most of the time, while it was stressful for others but this lessens to some extent as confidence grows with experience. However, this depended on the actual result and what they were instructed to tell the patient, with most agreeing the process was difficult when communicating 'bad news'.

Dealing with a patient's expectations and reactions when informed of a test result was also a challenge, with many participants' feeling pressurised into engaging in further discussions. When informed their results are normal, patients can sometimes appear to be 'unhappy', 'disappointed' or even 'astonished' that this is the case given their perceived clinical condition, leading them to seek clarification, double-checking and retesting. Some patients also assumed that administrative staff are able to interpret the result and provide further clarity. When informed a letter is to be sent to them, or if asked to return for a repeat blood test, patients may also become visibly anxious or agitated inducing stress and discomfort in staff who felt very limited and inadequate in terms of providing reassurance.

There was consensus that a clinician would ideally be the most appropriate person to communicate test results to reassure patients, provide further explanation and enhance safety. However, it was acknowledged by most that they have a job responsibility to perform this task and that in most cases test results are normal, while 
many of the complicated abnormal results and associated emotional impacts are usually, but not always, handled by practice clinicians.

Many often felt pressured to communicate to patients more than they are comfortable with, with some suggesting that giving results should not be part of their role because they are not clinically trained. For some, they feel at times 'pushed' by the patient to give them more information, however most recognise this as potentially 'dangerous' in terms of giving out inappropriate information and perhaps incurring the wrath of the doctors.

I don't even know what I am talking about and I am trying to explain [test results] to somebody. (Focus Group 2)

when I started giving out the results I was terrified I didn't relish the prospect (Focus Group 2)

I always feel a wee bit anxious when I am giving out these kind of results because for one you are not sure if what you are telling them is the right thing and you don't know how they are going to react (Focus Group 3)

we give out, for example, urine results although the GP's not seen them because it is absolutely spot on clear, we always say doctor hasn't seen this result yet it is a provisional result, should there be anything that the Doctor needs to talk to you about then we will get back to you, I put on that result 'patient informed negative for infection trust this was ok' that is my comment it goes back to the GP, it is always seen. (Focus Group 3)

I think a nurse or someone with some clinical background should be dealing with it. (Focus Group 2)

I find it hard when they are ringing for results and you need to make them an appointment and they go into panic at the end of the phone and you can't give them any more information, I am not medically trained I can't tell you then you have got nobody to ring them back. (Focus Group 1)

[communicating]a bad result...just as a human being there is something you are seeing [the result] before that patient knows. (Focus Group 5)

You don't want to get involved in conversations like that [going into detail about results], they just go wrong (Focus Group 5)

\section{Follow-up and confidentiality}

Failure to contact patients despite making numerous telephone calls and sending letters was a continual source of frustration, while patients failing to make contact for test results despite being instructed to at previous appointments emerged as key follow-up issues. Protecting patient confidentiality was a problematic area of practice, particularly in face-to-face situations in busy reception areas which lacked private spaces. Some participants would refuse to give results over the telephone if they were unable to verify the caller's identity, while others admitted to deviating from protocols by communicating results if they personally knew the patient or a relative, particularly where the patient was ill or had a disability. Caller identification systems also caused problems for staff and patients in circumstances where the practice number shows up on the patient's home telephone system and they subsequently telephoned back, but practice staff are not immediately aware who made contact with the patient and why, which causes additional delays and workload to resolve the issue.

The use of signed authorisation forms by the patient and automatic systems alerts to authorise permission to another person (eg, partner) to receive a result were also in common usage. However some practice policies insisted on seeing and receiving patients' authorisation in person, particularly where the patient did not speak English.

The practices of many participants had an age cut-off for parents who may telephone to receive their child's results on their behalf, which can cause upset and anger when administrative staff refuse to comply with parents' requests. When unable to contact patients by telephone leaving the practice contact number and not explaining who is telephoning and why, was a common policy for some. Others would not leave any message unless the patient had explicitly agreed to this. Some participants described potential breach of confidentiality incidents where colleagues had telephoned patients and left voicemail messages on home telephones explaining who was calling and to return the call to receive their blood test results.

Mixed work practices emerged over where and how to communicate test results with many participants favouring face-to-face contact rather than performing this task over the telephone, although some reported that patients can dislike telephone contact. Maintaining confidentiality at the reception desk was a major concern, with some practices preferring not to give out results here because it was difficult to maintain privacy, particularly when very busy. Some participants agreed the onus was on the patient in this situation and that if they choose to ask for test results in an area where they could potentially be over-heard then they were happy to communicate them, although in most cases patients are being informed that the result is normal or to telephone back.

a lot of them just don't phone back, you're maybe getting them three months down the line saying, I had bloods done. (Focus Group 2)

there are lots of issues at the front desk that can be an absolute nightmare for us...it is difficult you have got a crowd at the door and someone is wanting to get their [test] results. (Focus Group 4)

\section{DISCUSSION}

The main safety risks experienced and perceived by GP administrators in this study covered a wide range of system level weaknesses, doctor-administrator-patient 
communication issues, maintaining patient confidentiality, following up patients and coping with their reactions to, and expectations of, blood test results. Participants' accounts of systems, communication and psychosocial problems expose the potential for error, inefficiencies and frustrations associated with handling test results.

\section{Strengths and limitations}

The use of focus groups enabled us to explore this under-studied issue in greater depth with an important part of the relevant workforce than we would have done, for example, using a questionnaire survey. All participants who volunteered a willingness to participate actually attended the group interviews which may be an acknowledgement that this is an issue of high interest. The discussions were lively and we were satisfied that every participant was able to make an adequate contribution. Limitations include the fact that a convenience sample was used, whereas a purposively selected sample may have provided greater insights into relevant issues among a more diverse range of staff and practices. Selection bias may have been introduced due to a reliance on practice managers helping to recruit study participants from their own practices. This is because in the UK there is no other way of making direct contact with GP administrators as external health authorities do not hold personal database records of these staff groups in the same way as other (clinical) groups. We were also unable to link participants' views and experiences with the demographics of the practices in which they were based and the systems used, nor did we collect data on participants' age, gender or years of experience. Other limitations are that some practices use only nurses to communicate test results to patients while practices in geographical areas not covered use full electronic tracking systems for results handling. Addressing these issues would have enhanced the robustness of the study and the strength of our findings, which should be viewed with some caution given this context.

The reported weaknesses of practice systems is comparable with previous research which found that participants experienced multiple problems in the different process steps involved in results handling, with inadequate systems and lack of standardisation being identified as contributory factors. ${ }^{5}{ }^{26}$ Additionally, difficulties arising in the clarity of verbal and written communication between doctors and others, including the potential for perceived disrespect or rudeness, ${ }^{27}$ are a recognised hierarchal problem which may also impact on safety in the workplace. ${ }^{328}$ In this regard, there are recommendations for doctors to develop a greater understanding of the administrator's work role. ${ }^{1620}$ Although administrator-patient communication has been the subject of limited research previously-mainly focused on the administrator as a barrier to accessing care-our findings suggest that some administrators struggle with the interpersonal and emotional demands of informing patients of test results and handling follow-up queries.
Dealing with patients' sometimes difficult expectations and reactions, and feeling caught between the demands of doctors and patients are previously reported as workplace stressors for administrators in primary care. ${ }^{16}$ Finally, the issue of patient confidentially being breached in the reception waiting area is a known significant event, ${ }^{1}$ but can sometimes be difficult to mitigate given the lack of private space availability afforded in the design of healthcare facilities and the attitudes of staff and patients towards confidentiality. ${ }^{29} 30$

One way to interpret and explain the findings and consider the wider issue of test result handling at the practice level is to understand the workplace in terms of sociotechnical systems theory, which is highly influential in human factors science and application. ${ }^{30-32}$ In essence this suggests that the success of any workplace system or technology is strongly interdependent on the social relational contexts of work organisation, rather than just on the systems or technology itself. There is a growing interest in the need for healthcare professionals to be trained to understand and implement human factors and ergonomic principles in the workplace. ${ }^{23} 33$ Taking a systems approach to designing job tasks and work processes to accommodate human capabilities and limitations, and therefore minimise the risk of errors, is an important element of this discipline. ${ }^{33-35}$ There appears to be a clear alignment between many of the social and technical interactions and interdependencies of test results handling systems uncovered in this study (and the wider literature) that would benefit from a human factors approach.

Patient safety research is still in its infancy, particularly in primary care. ${ }^{11} 1236$ Although we know from limited taxonomy studies undertaken that test results handling is a major issue, ${ }^{1}{ }^{27-42}$ we need a more in-depth understanding of the related human-task-system interactions and sociotechnical risks inherent in the practice systems we design if potential solutions to problems are to be realised. ${ }^{43}$ Involving key staff groups such as administrators and using qualitative research methods to explore these issues is, therefore, paramount to advancing knowledge about practice culture (eg, leadership behaviours and commitment to improving safety), psychosocial issues (eg, staff motivation and input to relevant decision-making) and technical difficulties (eg, reliability of test result handling processes and information technology). Arguably all will have to be addressed before we can begin to make progress in redesigning and evaluating improved test result handling systems to minimise errors and patient harm.

\section{CONCLUSION}

The study further confirms the safety-related problems associated with results handling systems in primary care and add to our knowledge of the communication and psychosocial issues that can surface at the doctor-administrator and administrator-patient levels, potentially 
affecting the health and well-being of staff and patients alike. However, they provide an opportunity for practices to identify barriers to safe care, and plan and implement system improvements to accommodate or mitigate the potential for human error in this complex area. A potential learning need to develop educational solutions for the primary care workforce to strengthen human error knowledge, whole system awareness, team working and internal communications is also apparent.

Acknowledgements The authors would like to sincerely thank all administrative staff groups who attended the focus groups and made valuable contributions to our understanding of results handling systems and safe practice.

Contributors PB conceived the study idea, acquired funding, assisted with the study design, data analysis and interpretation and the drafting and critical revision of the manuscript. LH assisted with the study design, led the data collection, analysis and interpretation and helped draft the manuscript. JM contributed to the drafting and critical revision of the manuscript. All the authors have approved the manuscript.

Funding The research leading to these results has received funding from the European Community's Seventh Framework Programme FP7/2008-2012 under grant agreement number 223424. Additional funding was provided by National Health Service (NHS) Education for Scotland.

Competing interests None.

Ethics approval This study was prescreened by the west of Scotland research ethics committee but was judged to be service evaluation.

Provenance and peer review Not commissioned; externally peer reviewed.

Data sharing statement No additional data are available.

Open Access This is an Open Access article distributed in accordance with the Creative Commons Attribution Non Commercial (CC BY-NC 3.0) license, which permits others to distribute, remix, adapt, build upon this work noncommercially, and license their derivative works on different terms, provided the original work is properly cited and the use is non-commercial. See: http:// creativecommons.org/licenses/by-nc/3.0/

\section{REFERENCES}

1. McKay J, Bradley N, Lough M, et al. A review of significant events analysed in general medical practice: implications for the quality and safety of patient care. BMC Fam Pract 2009;10:61.

2. Elder NC, Dovey SM. Classification of medical errors and preventable adverse events in primary care: a synthesis of the literature. J Fam Pract 2002;51:927-32.

3. Elder NC, McEwan TR, Flach JM, et al. Management of test results in family medicine offices. Ann Fam Med 2009;7:343-51.

4. Mold JW. Management of laboratory test results in family practice: an OKPRN study. J Fam Pract 2000;49:709-15.

5. Elder NC, Graham D, Brandt E, et al. The testing process in family medicine: problems, solutions and barriers as seen by physicians and their staff. J Patient Saf 2006;2:25-32.

6. Poon EG, Gandhi TK, Sequist TD, et al. "I wish I had seen this test result earlier!" Dissatisfaction with test result management systems in primary care. Arch Intern Med 2004;164:2223-8.

7. Hickner JM, Fernald DH, Harris DM, et al. Issues and initiatives in the testing process in primary care physician offices. Jt Comm J Qual Patient Saf 2005;31:81-9.

8. Hickner J. Reducing test management errors in primary care office practice. J Patient Saf 2005;1:70-1.

9. Bird S. A GP's duty to follow-up test results. Aust Fam Phys 2003;32:45-6.

10. Kljakovic M. Patients and tests: a study into understanding of blood tests ordered by their doctor. Aust Fam Phys 2012;40:241-3.

11. The Scottish Government. Delivering quality in primary care national action plan: implementing the Healthcare Quality Strategy for NHS Scotland. Edinburgh: The Scottish Government, 2010:1-18.

12. LINNEAUS Euro-PC. Learning from international networks about errors and understanding safety in primary care. 2011. http://www. linneaus-pc.eu/ (accessed 7 Sep 2013).
13. Bird S. Missing test results and failure to diagnose. Aust Fam Physician 2004;33:360-1.

14. Hayes E. GP receptionists: their work and training. Health Visit 1989;62:117-18.

15. Copeman JP, van Zwanenberg TD. Practice receptionists: poorly trained and taken for granted? J R Coll Gen Pract 1988;38:14-16.

16. Eisner $\mathrm{M}$, Britten $\mathrm{N}$. What do general practice receptionists think and feel about their work? Br J Gen Pract 1999;49:103-6.

17. Alazri $M$, Heywood $P$, Leese $B$. How do receptionists view continuity of care and access in general practice? Eur J Gen Pract 2007;13:75-82.

18. Ward J, McMurray R. The unspoken word of general practitioner receptionists: a re-examination of emotion management in primary care. Soc Sci Med 2001;72:1083-7.

19. Magin P, Joyce T, Adams J, et al. Receptionists' experiences of occupational violence in general practice: a qualitative study. $\mathrm{Br} J$ Gen Pract 2009;59:578-83.

20. Parr $\mathrm{H}$, Holden J. How improving communication between GPs and receptionists can benefit your practice. Educ Prim Care 2012;23:350-9.

21. Albardiaz R. Communication skills and team-building for receptionists and ancillary staff. Educ Prim Care 2012;23:44-6.

22. Hesselgreaves $\mathrm{H}$, Lough $\mathrm{M}$, Power $\mathrm{A}$. The perceptions of reception staff in general practice about the factors influencing specific medication errors. Educ Prim Care 2009;20:21-7.

23. Bowie P, Forrest E, Price J, et al. Expert consensus on safe laboratory test ordering and results management systems in European primary care. Eur J Gen Pract (In Press).

24. Hsieh H-F, Shannon SE. Three approaches to content analysis Qual Health Res 2005;15:1277-88.

25. Downe-Wamboldt B. Content analysis: method, applications, and issues. Health Care Women Int 1992;13:313-21.

26. Elder NC, McEwn TR, Flach J, et al. The management of test results in primary care: does an electronic medical record make a difference? Fam Med 2010;42:327-33.

27. Flin R. Rudeness at work. BMJ 2010;340:c2480.

28. Beasley JW, Wetterneck TB, Tempt J, et al. Information chaos in primary care: implications for physician performance and patient safety. J Am Board Fam Med 2011;24:745-51.

29. Sokol D, Car J. Protecting patient confidentiality in telephone consultations in general practice. Br J Gen Pract 2006;56: 384-5

30. Sokol D, Car J. Patient confidentiality and telephone consultations: time for a password. J Med Ethics 2006;32:688-9.

31. Cherns A. The principles of sociotechnical design. Human Relations 1976;29:783-92.

32. Cherns A. Principles of sociotechnical design revisited. Human Relations 1987;40:153-62.

33. Reason J. Combating omission errors through task analysis and good reminders. Qual Saf Health Care 2002;11:40-4.

34. Clegg CW. Sociotechnical principles for system design. Appl Ergon 2000;31:463-77.

35. Elder NC, McEwen TR, Flach JM, et al. Creating safety in the testing process in primary care offices. Agency for Healthcare Quality and Research, 2007. http://www.ahrq.gov/professionals/quality-patientsafety/patient-safety-resources/resources/advances-in-patientsafety-2/vol2/Advances-Elder_18.pdf (accessed 10th Sep 2013).

36. The Health Foundation. Evidence scan: levels of harm in primary care. London, 2011. http://www.health.org.uk/publications/ levels-of-harm-in-primary-care/ (accessed: 10 Sep 2013).

37. Jacobs S, O'Beirne M, Derfiingher LP, et al. Errors and adverse events in family medicine: developing and validating a Canadian taxonomy of errors. Can Fam Physician 2007;53:271e6-270.

38. Makeham MA, Kidd MR, Salman DC, et al. The threats to patient safety (TAPs) study: incidence of reported errors in general practice. Med J Aust 2006;185:95-8.

39. O'Beirne M, Sterlin PD, Zwicker K, et al. Safety incidents in family medicine. BMJ Qual Saf 2011;20:1005-10.

40. Sandars J, Esmail A. The frequency and nature of medical error in primary care: understanding the diversity across studies. Fam Pract 2003;20:231-6.

41. Rubin G, George A, Chinn DJ, et al. Errors in general practice: development of an error classification and pilot study of a method for detecting errors. Qual Saf Health Care 2003;12:443-7.

42. Dovey SM, Meyers DS, Phillips RL Jr, et al. A preliminary taxonomy of medical errors in family practice. Qual Saf Health Care 2002;11:233-8.

43. de Savigny D, Adam T, eds. Systems thinking for health systems strengthening. Alliance for health policy and systems research. WHO, 2009. http://whqlibdoc.who.int/publications/2009/ 9789241563895 eng.pdf (accessed 1 Oct 2013). 